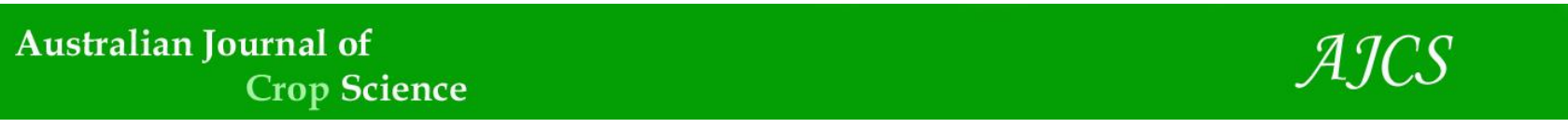

AJCS 15(02):233-237 (2021)

ISSN:1835-2707

doi: 10.21475/ajcs.21.15.02.p2785

\title{
Pollen fertility differences in the progenies obtained from a cross between eggplant (Solanum melongena L.) as a seed parent and eggplant cytoplasmic substitution lines as pollen parents
}

\author{
Shiro Isshiki ${ }^{1}$, Ichiro Nakamura ${ }^{2}$, Kenji Ureshino ${ }^{2}$, Md. Mizanur Rahim Khan ${ }^{2 *}$ \\ ${ }^{1}$ Faculty of Agriculture, Saga University, Saga 840-8502, Japan \\ ${ }^{2}$ Faculty of Agriculture, University of the Ryukyus, Okinawa 903-2213, Japan
}

*Corresponding author: khan@agr.u-ryukyu.ac.jp

\begin{abstract}
To the best of our knowledge, there is no report about pollen fertility of the progenies developed using eggplant (Solanum melongena L.) as a seed parent and eggplant cytoplasmic substitution lines as pollen parents. Pollen fertility of these progenies is very important to use as restorer line in the eggplant's hybrid breeding program. In this study, pollen fertility was investigated for the progenies which were produced using S. melongena 'Uttara' as a seed parent and the eggplant cytoplasmic substitution lines as pollen parents. To assess pollen fertility, pollen stainability and in vitro germination ability were investigated. Although the nuclear and the cytoplasmic genome of the progenies were almost identical to eggplant 'Uttara', a clear difference was observed in the pollen fertility due to the difference in the pollen parents having different wild Solanum cytoplasms. The progenies produced using the functional cytoplasmic male sterile (CMS) lines as a pollen parent, whose cytoplasm donor were S. kurzii, S. violaceum and S. virginianum, showed pollen release type and high pollen fertility almost equal to eggplant 'Uttara'. It is considered that the characteristics of these progenies were almost the same as eggplant. On the other hand, the progenies that produced using the fertility restored lines of the pollen non-formation type CMS lines as a pollen parent, whose cytoplasm donors were $S$. aethiopicum, S. anguivi and S. grandifolium, showed pollen release type and low pollen fertility, i.e., pollen staining ability was about $54 \%$ and pollen germination ability were about $35 \%$. It is considered that the cause of this low pollen fertility was the incompatibility between the eggplant cytoplasm and the eggplant nuclear genome, which seems to be modified in the process of continuous backcrossing under the wild Solanum cytoplasms. It is suggested that complete nuclear substitution is difficult by continuous backcrossing with eggplant in the alloplasmic lines with S. aethiopicum, S. anguivi and S. grandifolium cytoplasm donors. Incompatibility between the normal eggplant cytoplasm and the modified eggplant nuclear genomes of the alloplasmic lines with $S$. aethiopicum, S. anguivi and S. grandifolium cytoplasms might be a cause for the low pollen fertility of the investigated progenies.
\end{abstract}

Keywords: cytoplasmic substitution line; eggplant; male sterility; pollen fertility difference; wild Solanum species.

\section{Introduction}

In our laboratory, we have successfully developed six CMS systems of eggplant by developing cytoplasmic substitution lines utilizing the cytoplasms of six wild Solanum species closely related to eggplant through repeated backcrossing (Figs. 1 and 2). These CMS systems categorized into anther indehiscent and pollen non-formation types of sterility. CMS systems of eggplant developed utilizing the cytoplasms of $S$. kurzii Brace \& Prain, S. violaceum Ort. and S. virginianum L. expressed anther indehiscent type functional male-sterility (Isshiki and Kawajiri, 2002, Khan and Isshiki, 2008, 2009). On the other hand, CMS systems of eggplant developed utilizing the cytoplasms of $S$. aethiopicum L. Aculeatum Group, S. anguivi Lam. and S. grandifolium C.V. Morton expressed pollen non-formation type sterility (Khan and Isshiki, 2010, 2011, Hasnunnahar, et al., 2012). Pollen non-formation type CMS systems has male fertile line (fertility restorer line), which carries the fertility restorer $(R f)$ genes against pollen non-formation type sterility. At present, these CMS lines are being put to practical use for the production of $F_{1}$ seeds and/or seedless fruits of eggplant.

The traits of the wild Solanum species almost disappeared in the generation after the third generation of backcross, and the characteristics of the male sterility were stably expressed (Isshiki and Kawajiri, 2002, Khan and Isshiki, 2008, 2009, 2010, 2011, Hasnunnahar, et al., 2012). In this backcross generation, we attempted a reverse mating of the backcrossing, that is, an eggplant cultivar as a seed parent and the cytoplasmic substitution lines as a pollen parent for producing eggplant nuclear genome and cytoplasm with a nuclear Rf (restore fertility) gene/genes (Khan et al., 2013). These plants are predicted not to express male sterility because their cytoplasm is eggplant one and their pollen staining abilities are expected to be high almost equal to eggplant.

However, surprisingly, some of these plants showed low pollen staining ability when we examined the pollen fertility in the preliminary trial. This interesting phenomenon seems particularly noticeable in the progenies when fertility restored lines of the pollen non-formation type CMS lines used as a pollen parent. Therefore, we investigated the pollen fertility of 
each of the six progenies produced using eggplant as a seed parent and the six cytoplasmic substitution lines of wild Solanum species as a pollen parent in this study. Furthermore, the progenies of the backcrossing and the selfing of (eggplant $x$ the $\mathrm{BC}_{8}$ of $S$. anguivi), were examined for elucidating the cause of the low pollen fertility.

\section{Results and discussion}

\section{Pollen release ability}

Pollen release ability was investigated for each of the progenies produced using eggplant 'Uttara' as a seed parent and the six cytoplasmic substitution lines as a pollen parent. Each of the progenies was male fertile, i.e., pollen release type like eggplant 'Uttara'.

\section{Pollen fertility}

Although nuclear genome of the progenies was almost identical to eggplant 'Uttara', a clear difference was observed for pollen fertility when pollen parents from the two CMS systems differ. The progenies of the eggplant 'Uttara' $\times$ the functional CMS lines, whose cytoplasm donors were $S$. kurzii, $S$. violaceum and $S$. virginianum, showed high pollen fertility almost equal to eggplant 'Uttara' (Table 1, Figs. 3 and 4). It is considered that these progenies are almost the same to eggplant 'Uttara' for the characteristics of pollen release ability and pollen fertility. This may be since the alloplasmic cytoplasms of S. kurzii, S. violaceum and S. virginianum had no effect on the eggplant nuclear genome. These cytoplasms seem to be high affinity with the eggplant nuclear genome.

On the other hand, the progenies of the eggplant 'Uttara' $x$ the fertility restorer lines of the pollen non-formation type CMS systems, whose cytoplasm donors were $S$. aethiopicum, $S$. anguivi and S. grandifolium, showed low pollen fertility. Pollen staining ability was about $53 \sim 54 \%$ and pollen germination ability was about $34 \sim 38 \%$ (Table 2, Figs. 3 and 4). This may be due to the fact that each of the alloplasmic cytoplasm of $S$. aethiopicum, S. anguivi and S. grandifolium had a strong effect on eggplant nuclear genome. This strong effect means certain parts of the eggplant nuclear genome may have been modified. It is believed that the incompatibility between the normal eggplant cytoplasm and the modified eggplant nuclear genomes caused low pollen fertility. These cytoplasms seem not to have a high affinity with the eggplant nuclear genome.

In order to elucidate this further, we examined the progenies of backcrossing and selfing of the 'Uttara' $\times \mathrm{BC}_{8}$ of $S$. anguivi (Table 2). The pollen staining ability and germination ability of the backcrossed one were about $57 \%$ and $33 \%$. These values almost the same as the parental plant 'Uttara' $\times \mathrm{BC}_{8}$ of $S$. anguivi. This indicates that the fertility of the backcrossed one has not been recovered at all even if eggplant crossed once more. Therefore, it is suggested that depending on the cytoplasmic parents, complete nuclear substitution is difficult by continuous backcrossing with eggplant in the alloplasmic lines.

On the other hand, the pollen staining ability and germination ability of the selfed progenies were found in a recovery trend, which were about $90 \%$ and $42 \%$, respectively (Table 2 ). The recovery trend may be since the frequency of homozygosity of the modified eggplant nuclear genes increased through selfing. Of the six wild species surveyed this time, the five wild species, excluding S. grandifolium, have clarified their genetic distances based on ISSR variations (Isshiki et al., 2008). The respective genetic distance between eggplant 'Uttara' and the five wild species is similar in the dendrogram, however, there were differences in cross compatibility. This indicates that the cross incompatibility is not always related to the genetic distance between eggplant and wild Solanum species. There was a little cross incompatibility between eggplant and the three wild species, S. kurzii, S. violaceum and S. virginianum (Isshiki and Kawajiri, 2002, Khan and Isshiki, 2008, 2009). On the other hand, there was a considerable cross incompatibility between eggplant and the three wild species, S. aethiopicum, S. anguivi and S. grandifolium (Khan and Isshiki, 2010, 2011, Hasnunnahar, et al., 2012). When $F_{1}$ hybrids were made in the first cross to perform cytoplasmic substitution, they showed high hybrid sterility. It is thought that the difference in the presence or absence of the hybrid sterility might be one of a cause of the occurrence of this interesting phenomenon in the present study.

Prevalence of low pollen fertility found in the progenies between eggplant and the cytoplasmic substitution lines of eggplant having S. aethiopicum, S. anguivi and S. grandifolium cytoplasms is the first evidence in Solanum to our knowledge. Moreover, similar reports are also scarce in the case of cytoplasmic substitution lines of other vegetables. These findings would be valuable for elucidating speciation in Solanum, however, further studies should be needed to reveal the detailed mechanism.

\section{Materials and Methods}

\section{Plant materials}

Solanum melongena 'Uttara' was crossed with each of the six cytoplasmic substitution lines using 'Uttara' as a seed parent (cytoplasm parent) and cytoplasmic substitution lines of eggplant as pollen parents (Figs. 1 and 2). Forty seven seedlings of 'Uttara' $\times$ the $\mathrm{BC}_{5}$ of $S$. kurzii, 50 of 'Uttara' $\times$ the $\mathrm{BC}_{10}$ of $S$. violaceum, 69 of 'Uttara' $\times$ the $\mathrm{BC}_{5}$ of $S$. virginianum, 84 of 'Uttara' $\times$ the $\mathrm{BC}_{5}$ of S. aethiopicum, 82 of 'Uttara' $\times$ the $\mathrm{BC}_{8}$ of $S$. anguivi, 46 of 'Uttara' $\times$ the $\mathrm{BC}_{5}$ of $S$. grandifolium and their parental lines were used as the experimental materials. Further, 74 crossed seedlings of ('Uttara' $\times$ the $\mathrm{BC}_{8}$ of $S$. anguivi) $\times$ 'Uttara' and 69 selfed seedlings of ('Uttara' $\times$ the $\mathrm{BC}_{8}$ of $S$. anguivi) were also used for investigation of the present study.

\section{Pollen release ability}

Anther tips were observed under stereomicroscope for assessing pollen release ability. Anthers from 15 flowers were examined for each plant.

\section{Pollen fertility}

The pollen stainability and in vitro germination ability of pollen were investigated to assess pollen fertility. Pollen grains from freshly opened flowers were extracted from the anthers by dissection, then smeared in $1 \%(\mathrm{w} / \mathrm{v})$ acetic carmine to assess their staining ability using the method described by Singh (2002). The in vitro germination ability of pollen was investigated according to Singh (2002) with a slight modification using germination medium consisting of $1 \%(\mathrm{w} / \mathrm{v})$ 
Table 1. Pollen release ability, pollen stainability and pollen germination ability in the progenies that produced using Solanum melongena 'Uttara' as a seed parent and the functional type of CMS lines as a pollen parent.

\begin{tabular}{|c|c|c|c|}
\hline Plant materials & $\begin{array}{c}\text { Pollen release } \\
\text { ability }\end{array}$ & $\begin{array}{c}\text { Pollen } \\
\text { stainability }^{1}\end{array}$ & $\begin{array}{c}\text { Pollen germination } \\
\text { ability }^{1}\end{array}$ \\
\hline Solanum melongena 'Uttara' & + & 98.6 & 72.1 \\
\hline $\mathrm{BC}_{5}$ of $S$. kurzii & - & 58.2 & 4.6 \\
\hline $\mathrm{BC}_{10}$ of $\mathrm{S}$. violaceum & - & 41.8 & 2.8 \\
\hline $\mathrm{BC}_{5}$ of S. virginianum & - & 58.0 & 4.5 \\
\hline S. melongena 'Uttara' ${ }^{\circ} \times \mathrm{BC}_{5}$ of S. kurzii ${ }^{\wedge}$ & + & $92.6 \pm 0.9$ & $68.2 \pm 0.9$ \\
\hline S. melongena 'Uttara' ${ }_{+} \times \mathrm{BC}_{10}$ of $\mathrm{S}$. violaceum ${ }^{\lambda}$ & + & $95.3 \pm 0.3$ & $66.5 \pm 0.5$ \\
\hline S. melongena 'Uttara' $+\times \mathrm{BC}_{5}$ of $S$. virginianum ${ }^{\top}$ & + & $93.3 \pm 0.4$ & $67.2 \pm 0.7$ \\
\hline
\end{tabular}

(A)

S. kurzii $\times$ S. melongena 'Uttara'<smiles>[CH]=C</smiles>

$\mathrm{F}_{1}$ hybrid $\times$ S. melongena 'Uttara'

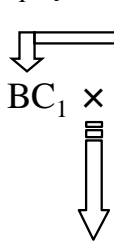

$\mathrm{BC}_{5}$

(B)

S. violaceum $\times$ S. melongena 'Uttara'<smiles>[CH]=C</smiles>

$\mathrm{F}_{1}$ hybrid $\times$ S. melongena 'Uttara'

$\mathrm{BC}_{1} \times$ 'Uttara' $\quad \mathrm{BC}_{1}$

号

$\mathrm{BC}_{10}$
Anther dehiscent

Anther indehiscent
Anther dehiscent

Anther indehiscent
(C) S. virginianum $\times$ S. melongena 'Uttara'<smiles>C1=CC=C1</smiles>

$\mathrm{F}_{1}$ hybrid $\times$ S. melongena 'Uttara'

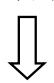

$\mathrm{BC}_{1} \times$ 'Uttara'<smiles>[C+]=C=[Bi]</smiles>

Anther dehiscent

Anther indehiscent

Fig 1. $\operatorname{Pr}^{1}$ ocedure for substituting the cytoplasms of S. kurzii (A), S. violaceum (B) and S. virginianum (C) for that of S. melongena 'Uttara' by continuous backcrossing.

1 Values represent the mean $\pm \mathrm{SE}$. 
Table 2. Pollen release ability, pollen stainability and pollen germination ability in the progenies that produced using Solanum melongena 'Uttara' as a seed parent and the fertility restored lines of the pollen non-formation type CMS lines as a pollen parent and their further progenies.

\begin{tabular}{|c|c|c|c|}
\hline Plant materials & $\begin{array}{c}\text { Pollen release } \\
\text { ability }\end{array}$ & $\begin{array}{c}\text { Pollen } \\
\text { stainability }^{1}\end{array}$ & $\begin{array}{c}\text { Pollen } \\
\text { germination } \\
\text { ability }^{1}\end{array}$ \\
\hline Solanum melongena 'Uttara' & & 98.6 & 72.1 \\
\hline $\mathrm{BC}_{5}$ of $S$. aethiopicum (CMS with $R f$ ) & + & 57.1 & 6.0 \\
\hline $\mathrm{BC}_{8}$ of $S$. anguivi (CMS with $R f$ ) & + & 53.5 & 25.4 \\
\hline $\mathrm{BC}_{5}$ of $S$. grandifolium $\quad$ (CMS with $R f$ ) & + & 53.0 & 1.5 \\
\hline S. melongena 'Uttara' $q \times \mathrm{BC}_{5}$ of $S$. aethiopicum (CMS with $\left.R f\right) \hat{\jmath}$ & + & $54.1 \pm 0.8$ & $38.2 \pm 0.94$ \\
\hline S. melongena 'Uttara' $q \times \mathrm{BC}_{8}$ of $S$. anguivi (CMS with $\left.R f\right) \hat{\jmath}$ & + & $54.6 \pm 0.8$ & $34.4 \pm 0.95$ \\
\hline S. melongena 'Uttara' $q \times \mathrm{BC}_{5}$ of $S$. grandifolium (CMS with $R f$ ) & + & $53.2 \pm 0.1$ & $35.1 \pm 0.16$ \\
\hline$\left\{{ }^{\prime} U\right.$ ttara' $\times \mathrm{BC}_{8}$ of S. anguivi (CMS with $\left.\left.R f\right)\right\}+\times$ 'Uttara' $\delta$ & + & $56.5 \pm 1.7$ & $32.9 \pm 1.57$ \\
\hline Selfing of $\left\{{ }^{\prime}\right.$ Uttara' $\times \mathrm{BC}_{8}$ of $S$. anguivi (CMS with $\left.\left.R f\right)\right\}$ & + & $89.6 \pm 0.9$ & $41.7 \pm 2.14$ \\
\hline
\end{tabular}

${ }^{1}$ Values represent the mean $\pm \mathrm{SE}$.

(A) S. aethiopicum $\times$ S. melongena 'DMP' Aculeatum Group 冏

$\mathrm{F}_{1}$ 'Assist' $\times$ S. melongena 'Uttara'

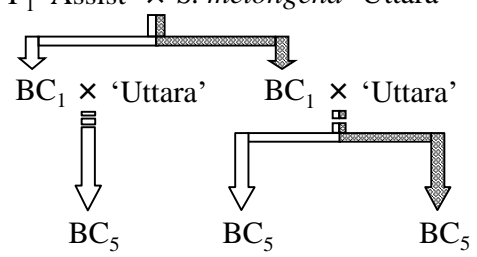

(B)

S. anguivi $\times$ S. melongena 'Senryo 2 gou'<smiles>c1ccccc1</smiles>

$\mathrm{F}_{1}$ hybrid $\times$ S. melongena 'Uttara'
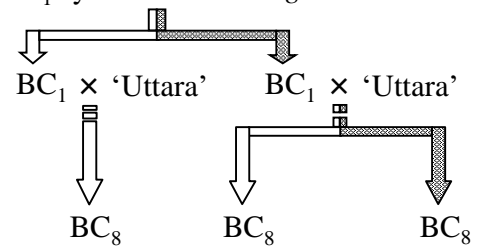

(C)

$$
\begin{aligned}
& \text { 'Taibyo VF' } \\
& \begin{array}{l}
\text { (S. grandifolium } \\
\times \text { S. melongena })
\end{array} \\
& \mathrm{BC}_{1} \times \text { S. melongena 'DMP' }
\end{aligned}
$$<smiles>BrC1=CC=CC1=C(Br)Br</smiles>

Uthara'
Male fertile

$\square$ Male sterile
Male fertile

$\square$ Male sterile

Fig 2. Procedure for substituting the cytoplasms of S. aethiopicum Aculeatum Group (A), S. anguivi (B) and S. grandifolium (C) for that of $S$. melongena 'Uttara' by continuous backcrossing.

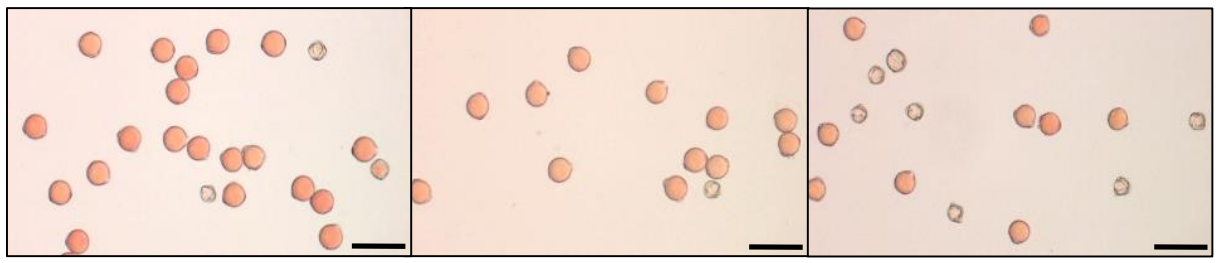

Fig 3.Pollen stainability of $S$. melongena 'Uttara' (A), a progeny of 'Uttara' $\times \mathrm{BC}_{5}$ of $S$. kurzii (B) and a progeny of ' $U$ ttara' $\times \mathrm{BC}_{8}$ of $S$. anguivi (CMS with $R f$ ) (C). 


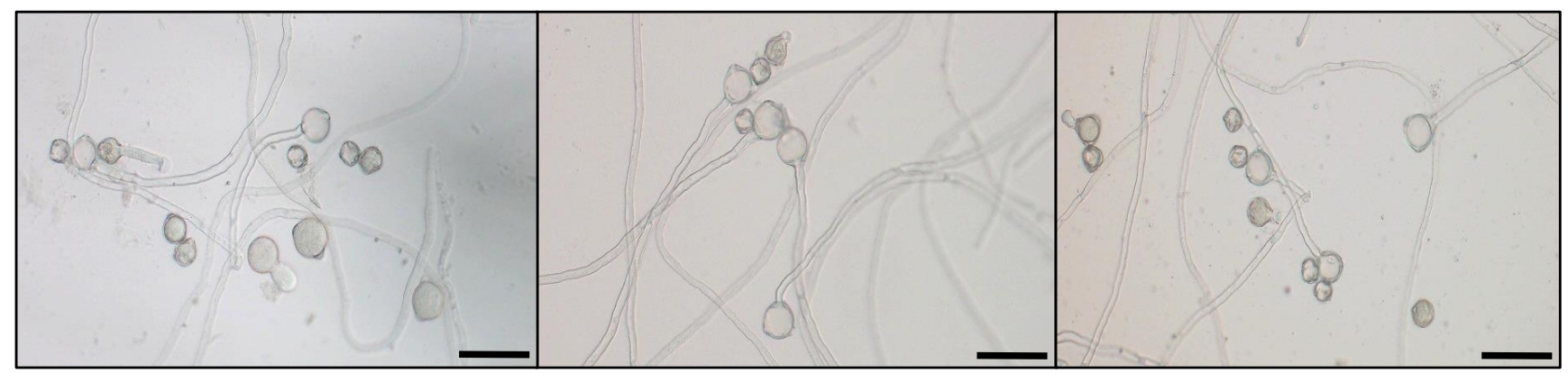

Fig 4. Pollen germination ability of $S$. melongena 'Uttara' (A), a progeny of 'Uttara' $\times \mathrm{BC}_{5}$ of $S$. kurzii (B) and a progeny of 'Uttara'

$\times \mathrm{BC}_{8}$ of $S$. anguivi (CMS with $\left.R f\right)(\mathrm{C})$.

agar, $5 \%$ sucrose and $50 \mathrm{mg} \mathrm{I}^{-1}$ boric acid.

\section{Conclusions}

Although it is presumed that the progenies produced using Solanum melongena eggplant 'Uttara' as a seed parent and the eggplant cytoplasmic substitution lines as pollen parents possess nuclear and cytoplasmic genome almost identical to eggplant 'Uttara', pollen fertility differences in the progenies compared to 'Uttara' might be due to the effect of wild Solanum cytoplasms of the pollen parents. In the cytoplasmic substitution lines, cytoplasms of $S$. kurzii, S. violaceum and $S$. virginianum had almost no effect on the eggplant nuclear genome. In contrast, cytoplasms of S. aethiopicum, S. anguivi and $S$. grandifolium had a strong effect which leads some modification in the eggplant nuclear genome. Incompatibility between the normal eggplant cytoplasm and the modified eggplant nuclear genomes of the alloplasmic lines might cause for the low pollen fertility of the investigated progenies.

\section{References}

Hasnunnahar M, Khan MMR, Isshiki S (2012) Inheritance of male fertility restoration of a male sterility system in eggplant with the cytoplasm of $S$. grandifolium. Aust J Crop Sci. 6: 475-479.

Isshiki S, Iwata N, Khan MMR (2008) ISSR variations in eggplant (Solanum melongena L.) and related Solanum species. Sci Hortic Amsterdam. 117: 186-190.

Isshiki S, Kawajiri N (2002) Effect of cytoplasm of Solanum violaceum Ort. on fertility of eggplant (S. melongena L.). Sci Hortic Amsterdam. 93: 9-18.

Khan MMR, Hasnunnahar M, Iwayoshi M, Isshiki S (2013) Pollen and seed fertility of the male fertile lines having the fertility restorer gene in three CMS systems of eggplant. Sci Hortic Amsterdam. 157: 39-44.

Khan MMR, Isshiki S (2008) Development of a male sterile eggplant by utilizing the cytoplasm of Solanum virginianum and a biparental transmission of chloroplast DNA in backcrossing. Sci Hortic Amsterdam. 117: 316-320.

Khan MMR, Isshiki S (2009) Functional male-sterility expressed in eggplant (Solanum melongena L) containing the cytoplasm of S. kurzii Brace \& Prain. J Hortic Sci Biotechnol. 84: 92-96.

Khan MMR, Isshiki S (2010) Development of the male-sterile line of eggplant utilizing the cytoplasm of Solanum aethiopicum L. aculeatum group. J Jpn Soc Hortic Sci. 79: 348-353.

Khan MMR, Isshiki S (2011) Development of a cytoplasmic male-sterile line of eggplant (Solanum melongena L.) with the cytoplasm of Solanum anguivi. Plant Breeding. 130: 256-260.

Singh RJ (2002) Plant Cytogenetics, 2nd edn. CRC Press Inc., Boca Raton, FL, USA. 21-22. 